\title{
Lifestyle Patternas Determinant of Overweight and Obesity among Young Adults
}

\author{
Eman R. El-Refaay1, Amel I. Ahmed2, Nagwa M. Salem3 \\ 1 Assistant lecturer in Community Health Nursing, 2 Prof. of Community Health Nursing, 3 Assist. \\ Prof. of Community Health Nursing, Mansoura University.
}

\begin{abstract}
Introduction:The prevalence of overweight and obesity are in continuous increasement all over the world. The management of obesity focuses on physical activity and healthy diet. Aim:the present study aimed at studying the lifestyle pattern as determinant of overweight and obesity among young adults.Method:Abaseline assessment survey study designwas utilized to accomplish this study. Convenience sampling technique was used to recruit total number of 132 young adults, who were invited through World Wide Web (WWW) for globalization.Results:The study revealed high prevalence of overweight among $50.8 \%$ of participantsand obesity among $29.6 \%$ of them. More than half of participants had poor knowledge score related to healthy diet and physical exercise. Significant relationship was found between participants' body weight and their level of knowledge and dietary lifestyle as predictors in regression modal. Conclusion: The prevalence rate of overweight and obesity among young adults was high. Young adults had a poor score level of knowledge related healthy diet and physical exercises. Majority of them had unsatisfactory lifestylepattern including dietaryand physical activity. Finally, it is recommended to develop and implement effective weight management intervention that is appropriate to young adults to adopt healthy lifestyle.
\end{abstract}

adult

Keywords:Lifestyle, Physical activity, Dietary habits, Weight management, Young 


\section{Introduction}

The young adult years have been recognized as an influential period for excess weight gain and unhealthy weight-related behaviors. overweight and obesity are among the most preventable causes of morbidity and mortality. Obesity and overweight are the fifth cause of death all over the world (Smith \& Smith, 2016;Soeliman \& Azadbakht, 2014).

This age group experiences the highest rates of weight gain across the life span (Roy, Rangan, \& Hebden, 2017). A cross sectional study conducted in Egypt revealed that 31.3\% of Egyptian adults are overweight and $10.3 \%$ of them are obese (Peltzer\&Pengpid, 2014).

Lifestyle modification is the gold -standard treatment for obesity. Lifestyle support plays an important role in successful weight management. (Dueñas, et al.,2017).

Maintaining a healthy body weight through proper nutrition and regular physical activity can help decrease a person's risk of developing serious health conditions such as high blood pressure, high cholesterol, diabetes, heart disease, stroke, and cancer. These activities can have a positive impact on overall well $\square$ being through better management of existing health conditions and improved quality of life. Several factors, such as access to healthy foods and safe places to engage in physical activity, affect a person's ability to eat a healthy diet, stay physically active, and achieve or maintain a healthy weight (United States Department of Health and Human Services, 2020).

There are many approaches for effective healthy dietary lifestyle that help in weight reduction. Low-fat diets with reduced caloric intake and meal- replacement diets are effective approaches in weight loss.Ultimately, the best diet is one that the individual will be able to follow consistently over time, and considerthe well balanced healthydiet(Semlitsch T.,Stigler F.L.,Jeitler K., Horvath K.,\&Siebenhofer, A., 2019).

It is well known that exercise is an integral part of any weight loss program. Adults would perform at least 150 minutes of moderate-intensity or 75 minutes of vigorous-intensity aerobic activity per week. Aerobic activity should be performed for at least 10 minutes per session and should be spread throughout the week. For additional health benefits, adults should increase their aerobic physical activity to 300 minutes of moderate-intensity or 150 minutes of vigorous-intensity aerobic activity per week. Adults should also engage in muscle-strengthening activities of moderate to high intensity that involve all major muscle groups on two or three days per week (U.S. Department of Health and Human Services, 2018; WHO,2020).

To provide appropriate intervention for controlling overweight and obesity, it is important to investigate the individual lifestylepatternas dietary pattern and physical activity which considered the most common reasons for this problem (Elvsaas, Giske,1Fure, and Juvet, 2017)

\section{Aim of the Study}

The aim of the study isinvestigating the lifestyle pattern as determinant of overweight and obesity among young adults. 
Method

Design

Abaseline assessment survey study designwas utilized to accomplish this study. The survey is a preliminary assessment of a quasi- experimental study.

\section{Setting}

This study was carried out at World Wide Web (WWW) for globalization because the internet has entered to daily life of all people and all age groups benefit from it regarding their need(Ghasemi, V., Rabiei, K., Davoodi, S., \& Rabiei, 2017).

\section{Participants and sampling:}

Convenient sampling technique was used to recruitparticipants of this study. Participants should be in age from 18 - to 30 years who are overweight or obese. Participants should have a BMI in the range of $25-40 \mathrm{~kg} / \mathrm{m}$. They should be free from any health condition that interferes with dietary habits such as diabetesmellitus, hypothyroidism, hyperthyroidism, and pregnancy.The sample size was calculated for the original study design (quasiexperimental), by assuming $\alpha$ level to equal $0.05, \beta$ level equal 0.20 and the desired power is $80 \%$, when the assumed mean difference in BMI 1.5 (3.9) after modification of lifestyle, with the size effect= 1 (Margaret, \& Howarth, 2014). The minimum required subjects by considering non respondents by adding $10 \%$ are 132 participants (Rosner, 1995).

\section{Data Collection}

Data was collected by using five online self-administered questionnaires that were developed by the researcher based up on relevant literature.

Tool I:Demographic data assessment questionnaire:

A structured questionnaire was developed by the researcher to assess demographic characteristics such as age, gender, education, residency area, and occupation.

Tool II: Online health assessment questionnaire:

A structuredself-administered questionnaire was used to assess nutritional health status of participants including anthropometric measurement such as body weight, height, and body mass index according to (CDC, 2020) and waist circumference. This questionnaire wase included weight, height, and waist circumference measurement procedures as well as online body mass index calculator.

Tool III:Online knowledge assessment questionnaire about healthy nutrition:

A structured self-administered questionnaire was used to assess the participants' knowledge regarding healthy nutrition and the components of different food stuffs. The tool was composed of four categories; (healthy diet and its component, causes of obesity, management of obesity, and benefits from healthy diet)all these categories were composed of 21 questions. One mark was awarded for each correctanswer. The total score of knowledge ranged from 0 to 21 . According to the researcher's cut of point, the knowledge level was categorized into three categories as:

Poor $=$ scores less than $50 \%$ of total scores (less than 10.5)

Fair $=$ scores $50 \%$ to less than $65 \%$ of total sores (10.5 to less than 13.65)

Good $=$ scores more than $65 \%$ of total scores (13.65 and more)

Tool IV: Online dietary habits assessment questionnaire:

A structured self-administered questionnaire was used to assess participants' lifestyle dietary habits which included two categories: dietary 
Eman R. El-Refaay1, Amel I. Ahmed2et. al.

pattern and weight management trial.Likert scale was used in all questions.This tool consisted of 23questions18 of them requiring a response on five-point Likert- rating scale with five continuums (never, rarely, sometimes, often, and always) and 3 question multiple choice.Scoring system was used as the following: never $=0$, rarely $=1$, sometimes $=2$, often $=3$, and always $=4$ for proper practice and reversed score for improper practice and 5 questions with yes and no response. The total score of the practice ranged from ( 0 to 72 marks) and was summed up for each member. The practice level was categorized into two categories as:unsatisfactory $=$ scores less than $65 \%$ of total scores ( 0 - less than 46.8 marks) and satisfactory $=$ scores $65 \%$ of total scores and more (46.8 and more)

Tool V: Online physical activities knowledge and practice assessment:

A structured self-administered questionnaire was used to assess the participants knowledgerelated to physical activities and their practice.

Frist part related to knowledge wascomposed of two categories (types of physical exercise, andbenefitsof physical exercise). One mark was awarded for each correct answer. The total score of knowledge ranged from 0 to 21 . According to the researcher's cut of point, the knowledge level was categorized into three categories as:

$\S$ Poor $=$ scores less than $50 \%$ of total scores (less than 10.5)

$\S$ Fair $=$ scores $50 \%$ to less than $65 \%$ of total sores (10.5 to less than 13.65)

$\S$ Good $=$ scores more than $65 \%$ of total scores (13.65 and more).

Second partrelated to practices was consisted of 6 questions with 11 marks. The scoring system of practice was consisted of two categoriesas: unsatisfactory $=$ scores less than $65 \%$ of total scores ( 0 - less than 7.15 marks) and satisfactory $=$ scores $65 \%$ of total scores and more (7.15- less than 11 marks).

Procedure

Ethical approval was obtained from the Research Ethics Committee of Faculty of Nursing, Mansoura University for conducting the study.Verbal consent was obtained from the participants after clarifying the aim of the study and ensuring confidentiality of data. Participants were informed that they have the right to withdraw at any time from the study without giving any reason.

All tools were developed by the researcher after reviewing the related literature. Validity of the developed tools was tested by the following: content validity by submitting the tools to a jury of 5 experts in the field of "community health nursing". Face validity by conducting a pilot study on $10 \%$ of study sample $(n=13)$. Reliability for the practice was done by using Cronbach's alpha and the result was 0.74 . Based on the collected information, the necessary modifications were done

Data was collected through online completion of self-administered questionnaires that was uploaded on the web sitewww.thehealthgrardens.com. Data collection tools included demographiccharacteristics,

anthropometric measurements of participants, their knowledge about healthy diet and physical activity, lifestyle dietary pattern,andtheir physical activities practices. Self-reported height and weight were used to calculatebody mass index (BMI), according (CDC, 2020)overweight in adults isdefined as $\mathrm{BMI} \geq 25.0$ to $<30.0$ and obesity as $\mathrm{BMI} \geq 30$. 0 . 
Data analysis. Statistical analyses were performed using the statistical software Stands for Statistical Product and Service Solutions (SPSS) v20. Arithmetic mean \pm standard deviation for continuous variables and percentages for categorical variable. Chi-square, fisher's exact and monte-Carlo test used to test association. They were tested for normality by Kolmogorov-Smirnov test. For correlation coefficienttesting, multiple linear regression was used. All tests were performed at a level of significance (Pvalue) equal or less than 0.05 was considered statistically significant.

\section{Results}

Table(1)shows that the age of the studied young adults ranged from 18 to 30 years with a mean age $24.69(3.104)$. Most of participant were female $(84.8 \%)$. As regards to their education $59.8 \%$ and $29.6 \%$ were graduated and post graduateduniversity students, respectively.

Table (2) represents that $50.8 \%$ of the young adults were overweight. while $18.2 \% \& 11.4 \%$ of them were within different degree of obesity,respectively. The mean of waist circumference was 83.56(10.36).

Table (3) indicates that $65.2 \%$ of the young adults had poor score level of knowledge about healthy diet and its component with a mean $4.27(1.76)$ in addition to $32.6 \%$ of them had poor score level of knowledge about healthy diet benefitswith a mean 2.3(0.93).In relation to causes and management of obesity , $7.6 \%$ and $9.8 \%$ had poor score level of knowledge with a mean 2.7(0.6) and 2.72(0.63)respectively. Moreover, the mean of total score level of knowledge was 13.67(2.58). Concerning physical activity, $66.7 \%$ of the participants had poor score level of knowledge about physical activity and its types with a mean $6.49(2.89)$ in addition to $6.1 \%$ of them had poor score level of knowledge about physical activity benefits with a mean 4.01(1.09). As a whole, $51.5 \%$ had poor score level of knowledge regards physical activity with a mean of total score level of knowledge was 10.5 (3.17).

Table (4) represents that $97 \%$ of the participants hadunsatisfactory score level of practice regarding dietary patternlifestyle with a mean 35.58 (6.1). On other hand $47.7 \%$ of young adults make weight lost trail in the last three months. whereas $27.3 \%$ of them followed regime. Regarding the type of regime, $14.4 \%$ of them followed low caloric diet, $8.3 \%$ followed low carb diet, and $4.5 \%$ followed intermittent fasting. Regarding to physical exercise lifestyle pattern, it was observed $77.1 \%$ and $12.12 \%$ preferred walk and bicyclingrespectively. while only $8.33 \%$ and $3.79 \%$ preferred football and yoga respectively. Regarding total practices, $93.2 \%$ of young adults had unsatisfactory score level of practice regarding physical activitylifestyle with a mean of total practices score 3.31 (2.24).

Table (5) illustrates that distribution of Young adults reported barrier to healthy eating. It was noticed that time, availability of fast food, and have no desire $75 \%, 45.45 \%$, and $15.91 \%$ respectively were the most common barriers. As regards to barriers to physical activity. It was observed that time, far from any gym, and have no desire $78.1 \%, \quad 25.8 \%$, and $16.7 \%$ respectively were the most common barriers.

Table (6) clarifies that there was statistically significant association between sex, and participants' total score level of knowledge and practices 
regarding healthy diet $\mathrm{P}=0.000$ and $\mathrm{P}=0.005$ respectively.

Moreover, there was statistically association between BMI and young adults' total score level of knowledge and lifestyle practices as regard to physical activity $\mathrm{P}=.01, \quad$ and $\mathrm{P}=.04$,respectively.On the other hand,there was not statistically significant association between sex, and young adults' total score level of knowledge and practices regarding physical activity $\mathrm{P}=0.52$, and 0.63 ,respectively. Moreover, there was not statistically association between BMI, and young adults' total score level of knowledge and practices regarding physical activity $\mathrm{P}=0.53$, and 0.7 ,respectively.

Table (7) indicates astatistically significant relation between weight as dependent variable andlevel of knowledge and practices concerning healthy diet as predictors $(\mathrm{F}=6.769$,

$\mathrm{P}=.002)$. Moreover, two predictors explained $9.5 \%$ of variance in weight $(\mathrm{R} 2=, 095)$. While level of practices to healthy diet contributed significantly to the modal $(\mathrm{B}=12.030 \& \mathrm{P}=.003)$ and level of knowledge did not contribute significantly to the modal $(\mathrm{B}=$ 3.534\&P $=.066)$.

\section{Discussion}

Overweight and obesity are the major health problem in last years. young adults are more vulnerable to overweight and obesity due to unhealthy lifestyle changes such as excessive snacking, unhealthy meal choices, and busy schedules leading to a decrease in time spent in physical activity (SmithJackson\& Reel,2012).

This study shows high prevalence of overweight and obesity among young adults $(50.8 \%, 29.6 \%$ respectively as reported byPeltzer, et al (2014) and Ukegbu et al., (2017).

Young adults are more motivated to lose weight for good appearance, improve their social image, and feel more confident (Corsino, Lin, Batch $\&$ Voils ,2013). The finding of this study showed that $27.3 \%$ of the participants makes weight loss trial.

Lack of knowledge of healthy food choices is known to negatively influence eating habits. consumption of unhealthy snack foods and lower consumption of fruits, and vegetables were associated with weight gain(Pelletier\& Laska,2013; Ukegbu, et al.,2017). This study reported that 65.2 $\%$ of participants had poor level of knowledge regarding healthy diet and its component. Therefore $97 \%$ of participant had unsatisfactory dietary practices.

Food choice and related attitudes among young adults have multiple determinants, with influences including perceived convenience, physical characteristics of food, social context, perceived cost(Lanoye Autumn, Gorin Amy A., \&LaRose ,2016) The most common barriers against healthy eating among participants in this study are lack of time and availability of fast food.

Physical activity is a modifiable risk factor for obesity and its consequences. The results of this study were in line with the study conducted by Ramezankhani et al., (2016)which reported that poor level of knowledge related to physicalactivity.Moreover 93.2 $\%$ of them had unsatisfactory practices concerning physical activity.

The most common barrier for physical activity were lake of time and lack of motivation. This is consistent with previousstudy(Ashton, Hutchesson ,Rollo, Morgan, \&Collins, 2017). 
Lifestyle modification have been reported as the most effective strategy to manage obesity and overweight. theses modification included limiting calories intake, eating fruits and vegetables, engaging in physical activity, and monitoring dairy and body weight(Liou \& Kulik, 2020 ; Cha et al., 2014).

The current study revealed statistically significant association between gender,and nutritional knowledge and dietary lifestyle as revealed in previous studies (Otsuka et al., 2020; Grzymisławska, Małgorzata,Puch,

Zawada,\&Grzymisławski,

2020).Moreover, there was statistically significant between BMI and nutritional knowledge and practices. This finding was consistent with the results of previous

studies(Valmórbida,Goulart,Busnello,\&P ellanda,2017;Gutiérrez-

Pliego,Camarillo-Romero,MontenegroMorales\&GarduñoGarcía,2016).

The finding of the present studyshowed no statistically significance between gender, knowledge and lifestyle related to physical activity which in contrast with the study conducted byEl Ansari, et al (2014)that concluded a diversity between gender in physical activity.Thus due to the majority of study group were female.

On the other hand, there was no statistical significance between BMI and physical exercise as reported by previous studywhich mentioned that there was no association between hours of exercise and BMI.( Martín , Vilar \&Barato, 2016).

\section{Conclusion}

The present study revealed high prevalence of overweight and obesity among young adults. Young adults had a poor score level of knowledge related to healthy diet and physical exercises. Most of them had unsatisfactory dietary and physical activity lifestyle pattern.

\section{Recommendations}

Based on the findings and conclusions drawn from the study, the following recommendations are suggested:

- Provide lifestyle modification intervention regarding dietary regimen and physical exercise, to encourage young adults to engage in different forms of physical activity.

- Implement effective weight management intervention that is appropriate to young adults to adopt healthy lifestyle

\section{Acknowledgement}

We appreciate the cooperation of the participants of this study for completing the research successfully and special thanks are given to the supervisors, and community health nursing staff for their support throughout the study.

Table 1: Young adult's demographic characteristics

\begin{tabular}{|c|c|c|}
\hline Items & $n=132$ & \% \\
\hline Age: & 4 & 3.0 \\
\hline From 18 to less than 20 & 59 & 44.7 \\
\hline From 20 to less than 25 & 69 & 52.3 \\
\hline From 25 to 30 & $\mathbf{2 4 . 6 9 ( 3 . 1 0 4 )}$ \\
\hline X(S.D) & 20 & 15.2 \\
\hline Gender: & 112 & 84.8 \\
\hline Male & 1 & .8 \\
\hline Female Education: & 13 & 9.8 \\
\hline Diploma & 79 & 59.8 \\
\hline Undergraduate & 39 & 29.6 \\
\hline Graduate &
\end{tabular}


Eman R. El-Refaay1, Amel I. Ahmed2et. al.

Table 2 Young adult's body mass index and waist circumference

\begin{tabular}{|c|c|c|}
\hline Items & $n=132$ & $\%$ \\
\hline Body mass index & 2 & 1.5 \\
\hline Under weight & 24 & 18.2 \\
\hline Normal weight & 67 & 50.8 \\
\hline overweight & 24 & 18.2 \\
\hline Mild obesity & 15 & 11.4 \\
\hline Moderate obesity & $\mathbf{2 8 . 4 9 ( 4 . 6 4 7 )}$ \\
\hline $\bar{X}($ S.D) & \multicolumn{2}{|c|}{} \\
\hline Waist circumference \\
\hline \multicolumn{3}{|c|}{ X.D.D) }
\end{tabular}

Table 3 Young adult'sknowledge level in relation tohealthy lifestyle related overweight and obesity

\begin{tabular}{|c|c|c|c|c|c|c|}
\hline \multirow{3}{*}{ Items } & \multicolumn{6}{|c|}{ Knowledge level } \\
\hline & \multicolumn{2}{|c|}{ Poor } & \multicolumn{2}{|c|}{ Fair } & \multicolumn{2}{|c|}{ Good } \\
\hline & $\mathrm{N}=\mathbf{1 3 2}$ & $\%$ & $\mathrm{~N}=132$ & $\%$ & $\mathrm{~N}=132$ & $\%$ \\
\hline Healthy diet and its components & $\wedge 7$ & $70 . Y$ & 11 & 14.7 & $r \wedge$ & YI.Y \\
\hline (SD) & \multicolumn{6}{|c|}{$4.27(1.76)$} \\
\hline Causes of obesity & $1 \cdot$ & V.7 & 19 & $1 \leqslant . \varepsilon$ & $1 \cdot r$ & VA. \\
\hline (SD) & \multicolumn{6}{|c|}{$2.7(0.6)$} \\
\hline Management of obesity & 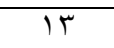 & $9 . \wedge$ & 11 & $\wedge . r$ & $1 \cdot 1$ & $\wedge . \wedge$ \\
\hline (SD) & \multicolumn{6}{|c|}{$2.72(0.63)$} \\
\hline Healthy diet benefits & $\varepsilon r$ & r. T & 7 & 4.5 & NT & TY. 9 \\
\hline (SD) & \multicolumn{6}{|c|}{$(9 r$.$) r.r.$} \\
\hline $\begin{array}{l}\text { Total knowledge level of dietary } \\
\text { habits }\end{array}$ & $1 \cdot$ & V. 7 & $7 \leq$ & $\leqslant \wedge .0$ & $0 \wedge$ & $\varepsilon r . q$ \\
\hline \pm SD & \multicolumn{6}{|c|}{$13.67(2.58)$} \\
\hline Physical exercise and its types & 88 & 66.7 & 31 & 23.5 & 12 & 9.1 \\
\hline (SD) & \multicolumn{6}{|c|}{$6.49(2.89)$} \\
\hline Benefits of physical activity & 8 & 6.1 & 25 & 18.9 & 99 & 75.0 \\
\hline (SD) & \multicolumn{6}{|c|}{ 4.01(1.09) } \\
\hline $\begin{array}{r}\text { Total knowledge level of physical } \\
\text { activity }\end{array}$ & 68 & 51.5 & 49 & 37.1 & 15 & 11.4 \\
\hline (SD) & \multicolumn{6}{|c|}{$10.5(3.17)$} \\
\hline
\end{tabular}

Note. Poor $=$ scores less than $50 \%$ of total scores

Fair $=$ scores $50 \%$ to less than $65 \%$ of total scores

Good $=$ scores $65 \%$ to $100 \%$ of total scores 
Lifestyle Patternas Determinant etc...

Table 4 Young adult's Pattern of dietary lifestyle and physical exercises

\begin{tabular}{|l|c|c|}
\hline Items & $\mathbf{N}=\mathbf{1 3 2}$ & $\%$ \\
\hline Dietary lifestyle pattern & 128 & 97.0 \\
\hline Unsatisfactory & 4 & 3.0 \\
\hline (SD) & \multicolumn{2}{|c|}{$\mathbf{3 5 . 5 8} \mathbf{( 6 . 1 )}$} \\
\hline Weight lost trail in the last 3 months & $\mathbf{6 3}$ & $\mathbf{4 7 . 7 \%}$ \\
\hline Adherence to one type of dietary regimen & $\mathrm{N}=36$ & $27.3 \%$ \\
\hline Intermittent fasting & 6 & $4.5 \%$ \\
\hline Low calories diet & 19 & $14.4 \%$ \\
\hline Low carbohydrate diet & 11 & $8.3 \%$ \\
\hline
\end{tabular}

\begin{tabular}{|l|c|c|}
\hline Physical exercise lifestyle pattern \\
\hline Unsatisfactory & 123 & 93.2 \\
\hline Satisfactory & 9 & 6.8 \\
\hline Total score =11 (SD) & \multicolumn{2}{|l|}{$\mathbf{3 . 3 1}(\mathbf{2 . 2 4})$} \\
\hline Moderate physical activity & 101 & 77.1 \\
\hline Walk & 5 & 3.79 \\
\hline Yoga & 2 & 1.52 \\
\hline Zumba & 16 & 12.12 \\
\hline Vigorous physical activity: & 11 & 8.33 \\
\hline Bicycling & 3 & 2.27 \\
\hline Football
\end{tabular}

Note. Unsatisfactory = scores less than Note. * The total number may be more $65 \%$ of total scores than 100 as more than one answer was Satisfactory $=65 \%$ and more of total score allowed forfavorite types of physical activity. 
Eman R. El-Refaay1, Amel I. Ahmed2et. al.

Table 5Young adults reported barrier of healthy lifestyle in relation todietary habits and physical activity *

\begin{tabular}{|l|c|c|}
\hline Items & $n=132$ & $\%$ \\
\hline Barriers to healthy eating & \multicolumn{2}{|l|}{} \\
\hline Limited time & 99 & 75 \\
\hline Availability of fast food & 60 & 45.45 \\
\hline Food cost & 9 & 6.82 \\
\hline Have no desire & 21 & 15.91 \\
\hline Have no support from others & 7 & 5.3 \\
\hline Barriers to physical activity & & \\
\hline Limited time & 103 & 78.1 \\
\hline Far from any gym & 34 & 25.8 \\
\hline Have no desire & 22 & 16.7 \\
\hline
\end{tabular}

* The total number may be more than 100 as more than one answer was allowed

Table 6Association between young adults' sex and BMI and their level of knowledge and lifestyle pattern related diet and physical exercise

\begin{tabular}{|c|c|c|c|c|c|c|c|c|c|c|c|c|c|c|c|c|}
\hline \multirow{4}{*}{\multicolumn{3}{|c|}{ Items }} & \multirow{2}{*}{\multicolumn{6}{|c|}{$\begin{array}{c}\text { Total score level of } \\
\text { Knowledge }\end{array}$}} & \multirow{4}{*}{$\begin{array}{l}\text { Test } \\
\text { of } \\
\text { significance }\end{array}$} & \multirow{4}{*}{$P$} & \multirow{3}{*}{\multicolumn{4}{|c|}{$\begin{array}{l}\text { Total score level of practice } \\
\text { Unsatisfactory Satisfactory }\end{array}$}} & \multirow{5}{*}{\multicolumn{2}{|c|}{$\begin{array}{c}\begin{array}{c}\text { Test } \\
\text { of } \\
\text { significance }\end{array} \\
\text { FE }\end{array}$}} \\
\hline & & & & & & & & & & & & & & & & \\
\hline & & & \multicolumn{2}{|c|}{ Poor } & \multicolumn{2}{|c|}{ Fair } & \multicolumn{2}{|c|}{ Good } & & & & & & & & \\
\hline & & & $\mathbf{N}$ & $\%$ & $\mathbf{N}$ & $\%$ & $\mathbf{N}$ & $\%$ & & & $\mathbf{N}$ & $\%$ & $\mathbf{N}$ & $\%$ & & \\
\hline \multirow{4}{*}{ Sex } & \multirow{2}{*}{ Male } & $\mathrm{D}$ & 5 & 3.8 & 141 & 10.6 & 1 & .8 & $\mathrm{MC}$ & $0.000^{*}$ & 14 & 10.6 & 6 & 4.5 & & $0.005^{*}$ \\
\hline & & P A & 8 & 6.1 & 9 & 6.8 & 3 & 2.3 & $\mathrm{X}^{2}$ & 0.52 & 18 & 13.8 & 2 & 1.5 & FE & 0.63 \\
\hline & \multirow{2}{*}{ Female } & $\mathrm{D}$ & 5 & 3.8 & \multirow{2}{*}{\multicolumn{4}{|c|}{\begin{tabular}{|l|l|l|l|}
50 & 37.9 & 57 & 43.2 \\
40 & 30.3 & 12 & 9.1 \\
\end{tabular}}} & $\mathrm{MC}$ & $.000^{*}$ & 105 & 79.5 & 7 & 5.3 & FE & $0.005^{*}$ \\
\hline & & P A & 60 & 45.5 & & & & & $\mathrm{X}^{2}$ & 0.52 & 103 & 79.2 & 7 & 5.4 & FE & 0.63 \\
\hline \multirow{10}{*}{ BMI } & \multirow{2}{*}{$\begin{array}{l}\text { Under } \\
\text { weight }\end{array}$} & D & 0 & 0 & 1 & .8 & 1 & 0.8 & \multirow{10}{*}{$\mathrm{MC}$} & $0.01 *$ & 2 & 1.5 & 0 & 0 & \multirow{10}{*}{$\mathrm{MC}$} & $0.04 *$ \\
\hline & & P A & 0 & 0 & 2 & 1.5 & 0 & 0 & & .53 & 2 & 1.5 & 0 & 0 & & 0.7 \\
\hline & \multirow{2}{*}{$\begin{array}{c}\text { Normal } \\
\text { weight }\end{array}$} & D & 2 & 1.5 & 5 & 6.7 & 17 & 12.9 & & $0.01 *$ & 24 & 18.2 & 0 & 0 & & $0.04 *$ \\
\hline & & P A & 13 & 9.8 & 9 & 6.8 & 2 & 1.5 & & .53 & 22 & 16.9 & 2 & 1.5 & & 0.7 \\
\hline & \multirow{2}{*}{ overweight } & D & 4 & 3 & 423 & 31.8 & 821 & \multirow{2}{*}{\begin{tabular}{|l|}
15.9 \\
6.1
\end{tabular}} & & $0.01 *$ & 58 & 43.9 & 9 & 6.8 & & \multirow{2}{*}{\begin{tabular}{|c|}
$0.04^{*}$ \\
0.7
\end{tabular}} \\
\hline & & P A & 3828.8 & 28.8 & 211 & 15.9 & 8 & & & .53 & 59 & 45.4 & 6 & 4.6 & & \\
\hline & \multirow{2}{*}{$\begin{array}{c}\text { Mild } \\
\text { obesity }\end{array}$} & D & 4 & 3 & 12 & 9.1 & 8 & 6.1 & & $0.01 *$ & 24 & 18.2 & 0 & 0 & & $0.04 *$ \\
\hline & & P A & 8 & 6.1 & 12 & 9.1 & 4 & 3 & & .53 & 23 & 17.7 & 1 & 0.8 & & 0.7 \\
\hline & \multirow{2}{*}{$\begin{array}{c}\text { Moderate } \\
\text { obesity }\end{array}$} & D & 1 & .8 & 3 & 2.3 & 11 & 8.3 & & $0.01 *$ & 11 & 8.4 & 4 & 3 & & $0.04 *$ \\
\hline & & P A & 9 & 6.9 & 5 & 3.8 & 1 & 0.8 & & .53 & 15 & 11.6 & 0 & 0 & & 0.7 \\
\hline
\end{tabular}

Note.

MC: Monte Carlo test $\mathrm{X}^{2}$ : Chi-square test

FE: Fisher's Exact Test

P: Significant $(p \leq 0.05)$

D: Dietary PA: Physical exercise 
Table 7Relation between young adults' total scoreslevel of knowledge and total score of lifestyle practice about healthy diet and weight as dependent variable

\begin{tabular}{|c|c|c|c|c|c|c|c|c|c|}
\hline $\begin{array}{c}\text { Dependent } \\
\text { variable }\end{array}$ & Predictors & $\mathbf{R}$ & $\mathbf{R 2}$ & $\mathbf{F}$ & $\mathbf{P}$ & Beta & $\mathbf{T}$ & $\mathbf{P}$ & VIF \\
\hline \multirow[b]{2}{*}{ Weight } & $\begin{array}{c}\text { Score's level of } \\
\text { knowledge related to } \\
\text { healthy diet }\end{array}$ & \multirow[b]{2}{*}{.308} & \multirow[b]{2}{*}{.095} & \multirow[b]{2}{*}{6.769} & \multirow[b]{2}{*}{$.002 * *$} & .156 & 1.854 & .066 & 1.005 \\
\hline & $\begin{array}{c}\text { Score's level of } \\
\text { practice related to } \\
\text { healthy diet }\end{array}$ & & & & & .255 & 3.039 & $.003 * *$ & 1.005 \\
\hline
\end{tabular}

Note.

$R$ : Regression

F: ANOVA

P: Significance of Test

** Highly significant $(p \leq 0.01)$

VIP: Varianceinflation factors

\section{References}

Ashton, L. M., Hutchesson, M. J., Rollo, M. E., Morgan, P. J., \& Collins, C. E. (2017). Motivators and Barriers to Engaging in Healthy Eating and Physical Activity: A Cross-Sectional Survey in Young Adult Men. American Journal of Men's Health, 11(2), 330-343. https://doi.org/10.1177/155798831 $\underline{6680936}$

CDC, (2020). Healthy weight, nutrition, and physical activity. https://www.cdc.gov/healthyweigh t/assessing/bmi/adult_bmi/index.ht $\underline{\mathrm{ml}}$

Cha, E. S., Kim, K. H., Lerner, H. M., Dawkins, C. R., Bello, M. K., Umpierrez, G., \& Dunbar, S. B. (2014). Health literacy, selfefficacy, food label use, and diet in young adults. American Journal of Health Behavior, 38(3), 331-339. https://doi.org/10.5993/AJHB.38.3 .2

Cochran, W. G. 1963. Sampling Techniques, 2nd Ed.,New York: John Wiley and Sons, Inc.

Corsino L, Lin PH, Batch BC, VoilsCI( 2013).Recruiting young adults into a weight loss trial: Report of protocol development and recruitment results. Contemp Clin Trials. 35(2):1-7.

Dueñas, S., Arnoriaga, M., Brizuela, A., Jhangiani, N., Gambino, R., B. Young, J., \&Burguera, B. (2017). Information and communication technology in obesity. Integrative Obesity and Diabetes, 3(4), 1-5. https://doi.org/10.15761/iod.10001 84

El Ansari, W., Khalil, K., Crone, D., \& Stock, C. (2014). Physical activity and gender differences: Correlates of compliance with recommended levels of five forms of physical activity among students at nine universities in Libya. Central European Journal of Public Health, 22(2), 98-105. https://doi.org/10.21101/cejph.a40 11

Elvsaas, I. K. Ø., Giske, L., Fure, B., \& Juvet, L. K. (2017). Multicomponent Lifestyle Interventions for Treating Overweight and Obesity in Children and Adolescents: A Systematic Review and MetaAnalyses. Journal of Obesity, 2017.

https://doi.org/10.1155/2017/5021 902

Ghasemi, V., Rabiei, K., Davoodi, S., \&Rabiei, H. (2017). Mobile Internet Usage among Adolescents 
Eman R. El-Refaay1, Amel I. Ahmed2et. al.

and Young Adults in Iran: A Sociological Survey. 863-878. https://doi.org/10.7596/taksad.v6i1 .785

Grzymisławska, M., Puch, E. A., Zawada, A., \&Grzymisławski, M. (2020). Do nutritional behaviors depend on biological sex and cultural gender? Advances in Clinical and Experimental Medicine, 29(1), 165-172. https://doi.org/10.17219/acem/111 $\underline{817}$

Gutiérrez-Pliego, L. E., Del Socorro Camarillo-Romero, E., Montenegro-Morales, L. P., \& De Jesus Garduño-García, J. (2016). Dietary patterns associated with body mass index (BMI) and lifestyle in Mexican adolescents. BMC Public Health, 16(1), 1-7. https://doi.org/10.1186/s12889016-3527-6

Lanoye Autumn, Gorin Amy A., L. J. G. (2016). Young Adults' Attitudes and Perceptions of Obesity and Weight Management: Implications for Treatment Development. In Current obesity reports (Vol. 5, Issue 1, pp. 1422).

https://doi.org/10.1007/s13679016-0188-9

Liou, D., \& Kulik, L. (2020). Selfefficacy and psychosocial considerations of obesity risk reduction behaviors in young adult white Americans. PLoS ONE, 15 (6 June), 1-12. https://doi.org/10.1371/journal.pon e.0235219

Margaret, M., \& Howarth, E. (2014). A Web-Based Weight Loss Programme Including Breakfast Cereals Results in Greater Loss of Body Mass than a Standardised
Web-Based Programme in a Randomised Controlled Trial, 361-375.

https://doi.org/10.1159/000369193

Otsuka, Y., Kaneita, Y., Itani, O., Jike, M., Osaki, Y., Higuchi, S., \& Kanda, H. (2020). Gender differences in dietary behaviors among Japanese adolescents. Preventive Medicine Reports, 20(September), 101203. https://doi.org/10.1016/j.pmedr.20 20.101203

Pelletier, J.E.; Laska， M.N. (2013) Campus food and beverage purchases are associated with indicators of diet quality in college students. Am. J. Health Promot., $28,80-87$

Peltzer, K., Pengpid, S., Alafia Samuels, T., ??zcan, N. K., Mantilla, C., Rahamefy, O. H., Wong, M. L., \&Gasparishvili, A. (2014). Prevalence of overweight/obesity and its associated factors among university students from 22 countries. International Journal of Environmental Research and Public Health, 11(7), 7425-7441. https://doi.org/10.3390/ijerph1107 $\underline{07425}$

Ramezankhani, A., Tavassoli, E., Ghafari, M., Alidosti, M., Daniali, S. S., \&Gharlipour, Z. (2016). Physical activity in adolescent girls and their perceptions of obesity prevention in Shahr-e Kord, Iran. International Journal of Pediatrics, 4(8), 3249-3262. https://doi.org/10.22038/ijp.2016.7 $\underline{320}$

Rosner B.(1995). Fundamentals of Biostatistics. 4th ed. Duxbury Press; 1995. Page 221 
Roy, R., Rangan, A., \& Hebden, L., (2017). Dietary contribution of foods and beverages sold within a university campus and its effect on diet quality of young adults. Nutrition, 34, 118-123. https://doi.org/10.1016/j.nut.2016. $\underline{09.013}$

San Mauro Martín, I., GaricanoVilar, E., \& Paredes Barato, V. (2016). Exercise and Body Mass Index: are those two parameters related in adults? Journal of Negative \& No Positive Results, 1(1), 36-41. https://doi.org/10.19230/jonnpr.20 16.1.1.935

Semlitsch, T., Stigler, F. L., Jeitler, K., Horvath, K., \&Siebenhofer, A. (2019). Management of overweight and obesity in primary care-A systematic overview of international evidence-based guidelines. Obesity Reviews, 20(9), 1218-1230. https://doi.org/10.1111/obr.12889

Smith, K. B., \& Smith, M. S. (2016). Obesity Statistics. Primary Care Clinics in Office Practice, 43(1), 121-135.

https://doi.org/10.1016/j.pop.2015. 10.001

Smith-Jackson. T and Reel J. J., (2012) "Freshmen women and the 'Freshman 15': perspectives on prevalence and causes of college weight gain," Journal of American College Health, vol. 60, no. 1, pp. 14-20.

Soeliman, F. A., \&Azadbakht, L. (2014). Weight loss maintenance: A review on dietary related strategies. Journal of Research in Medical Sciences: The Official
Journal of Isfahan University of Medical Sciences, 19(3), 268-275. http://www.ncbi.nlm.nih.gov/pub med/24949037

U.S. Department of Health and Human Services. (2018). Physical activity guidelines for Americans. The Oklahoma Nurse, 53(4), 113. https://doi.org/10.1249/fit.0000000 $\underline{000000472}$

United States Department of Health and Human Services,(2020) https://www.healthypeople.gov/20 20/leading-health-indicators/2020lhi-topics/Nutrition-PhysicalActivity-and-Obesity

Ukegbu, P. O., Uwaegbute, A. C., Echendu, C. A., Ejike, C., AnyikaElekeh, J. U., Asumugha, V. U., Kuyik, S. A., Omodamiro, S., Nwofia, B., Uzokwe, C., OluchiNliam, C., \&Uwakwe, N. (2017). Obesity and associated factors in young adults attending tertiary institutions in south-eastern Nigeria. South African Journal of Clinical Nutrition, 30(2), 43-48. https://doi.org/10.1080/16070658. 2016.1259032

Valmórbida, J. L., Goulart, M. R., Busnello, F. M., \&Pellanda, L. C. (2017). Nutritional knowledge and body mass index: A crosssectional study. Revista Da Associacao Medica Brasileira, 63(9), 736-740. https://doi.org/10.1590/18069282.63.09.736

WHO,(2020).Physical activity https://www.who.int/newsroom/fact-sheets/detail/physicalactivity 